\title{
Encapsulated baits containing zinc sulfate and Trichoderma harzianum reduce fungal garden in Atta sexdens colonies
}

\section{Daniella Gonçalves da Silva ${ }^{1}$, Aldemir Lucena Júnior ${ }^{1}$, Renato de Almeida Sarmento ${ }^{1}$, Cynthia Lhourrana Santos Silva ${ }^{1}$, Amanda Caroline Teles Tenório ${ }^{1}$, Danival José de Souza ${ }^{1}$, Márcio Silva Melo ${ }^{1}$}

\author{
${ }^{1}$ Universidade Federal do Tocantins, Campus de Gurupi, Gurupi, Tocantins, Brasil. E-mail: ellapgtu@ yahoo.com.br, \\ aldemirlucena@outlook.com, rsarmento@uft.edu.br, cynthialhourrana15@gmail.com, amandacttenorio@live.com, \\ danival@uft.edu.br, marciosilvagemeo@gmail.com
}

Received: 22/05/2020; Accepted: 13/07/2020.

\begin{abstract}
The aim of the study was to test the effects of various concentrations of zinc sulfate $\left(\mathrm{ZnSO}_{4}\right)$ on the radial growth of Trichoderma harzianum and Leucoagaricus gongylophorus in Petri dishes. In addition, we investigated the acceptance of baits containing live propagules of the encapsulated $T$. harzianum fungus and baits containing $\mathrm{ZnSO}_{4}$ by foraging leafcutter worker ants, $A$. sexdens, as well as their effects on the colonies of these ants. For the in vitro test, the design was completely randomized using ten replicates of a $2 \times 7$ factorial scheme: two species of fungi (T. harzianum and L. gongylophorus) and seven concentrations of $\mathrm{ZnSO}_{4}$. For bait acceptance tests, four treatments were used: baits without the mycelium and $\mathrm{ZnSO}_{4}(\mathrm{~T} 1$, control), baits containing encapsulated $T$. harzianum mycelium (T2), baits containing $\mathrm{ZnSO}_{4}$ (T3), and baits containing zinc sulfate and the encapsulated T. harzianum (T4). Each treatment was tested in duplicates using eight colonies. In the in vitro test, a $\mathrm{ZnSO}_{4}$ concentration of $0.25 \mathrm{~g} / \mathrm{L}$ was sufficient to completely inhibit the development of L. gongylophorus without affecting the development of T. harzianum. In the bait acceptance test, the workers accepted $\sim 55 \%$ of the bait combination of $\mathrm{ZnSO}_{4}$ and T. harzianum. This suggests the potential of treatment T4 in controlling leafcutter ants. Moreover, treatment T4 is environmentally friendly.
\end{abstract}

Keywords: antagonistic fungus, biological control, heavy metals, leafcutter ant, resistance.

Iscas encapsuladas contendo sulfato de zinco e Trichoderma harzianum reduzem o jardim de fungo em colônias de Atta sexdens

\section{RESUMO}

O objetivo deste trabalho foi testar os efeitos de diferentes concentrações de sulfato de zinco $\left(\mathrm{ZnSO}_{4}\right)$ no crescimento radial de Trichoderma harzianum e Leucoagaricus gongylophorus em placas de Petri. Além disso, investigou-se a aceitação de iscas contendo propágulos vivos do fungo $T$. harzianum encapsulado e iscas contendo $\mathrm{ZnSO}_{4}$ pelas operárias forrageadoras da formiga-cortadeira A. sexdens, bem como seus efeitos nas colônias dessas formigas. Para o teste in vitro, o delineamento foi inteiramente casualizado, com dez repetições de esquema fatorial $2 \times 7$, com duas espécies de fungos (T. harzianum e L. gongylophorus) e sete concentrações de $\mathrm{ZnSO}_{4}$. Para os testes de aceitação da isca foram utilizados quatro tratamentos: iscas sem micélio e sem ZnSO4 (T1, controle), iscas contendo micélio encapsulado T. harzianum (T2), iscas contendo $\mathrm{ZnSO}_{4}$ (T3) e iscas contendo sulfato de zinco e $T$. harzianum encapsulado (T4). Cada tratamento foi testado em duplicatas, usando um total de oito colônias. No teste in vitro, uma concentração de $\mathrm{ZnSO}_{4}$ de $0,25 \mathrm{~g}$ / L foi suficiente para inibir completamente o desenvolvimento de L. gongylophorus sem afetar o desenvolvimento de T. harzianum. No teste de aceitação da isca, as operárias transportaram $\sim 55 \%$ da combinação de isca de $\mathrm{ZnSO}_{4}$ e $T$. harzianum. O tratamento T4 é mais provável de ser significativo nas próximas experiências no campo. Sulfato de zinco e os fungos antagonistas do fungo mutualista das cortadeiras pode ser uma alternativa viável e ambientalmente segura no controle de formigas.

Palavras-chave: fungo antagonista, controle biológico, metais pesados, formiga-cortadeira, resistência. 


\section{Introduction}

Leafcutter ants of the genus Atta (Hymenoptera: Formicidae) are a problematic pest in Brazilian forests. Ants may attack plants at any stage of development. The cutting of leaves, shoots, thin branches, and flowers causes damage to the plants. The plant materials are carried into an underground nest and used as a substrate for the development of the symbiotic fungus $L$. gongylophorus that is cultivated by the ants (Della Lucia, 2011). Leucoagaricus gongylophorus degrades the foliar polysaccharides (i.e., pectin, starch, and cellulose) and converts them into glycogen for easy nutrient assimilation; the glycogen is stored in reserve structures called gongylidia, which are used as a source of food by the ants (Aylward et al., 2012). All fungus-growing ants belong to the tribe Attini, a clade that recently included genera of ants with certain other nutritional habits (Ward et al., 2015). In the symbiotic ant-fungus relationship, both the species are favored: the fungus is used in the diet of the ants, which in turn, provide substrates for fungus development, protection against their parasites and competitors, and ensures their propagation (Fine Licht et al., 2014; Lange and Grell, 2014).

Ants of the genus Atta have complex biological and behavioral characteristics that make their control difficult, such as architecture, size, and location of the nests, the queen protection system, and their defense strategies (Della Lucia et al., 2014; Montoya-Lerma et al., 2012). There is market pressure to reduce the use of the leading chemical pesticides used today to control leafcutter ants in forest stands. For example, the Forest Stewardship Council (FSC), an international certification system, has prohibited usage of several active ingredients, including deltamethrin, fenitrothion, fipronil, and sulfluramid (FSC, 2017) for controlling ants. Consequently, forestry companies in Brazil and elsewhere face challenges in adhering to the criteria required by the certification systems to use chemical pesticides due to the absence of alternatives for an integrated management of many pests (Zanuncio et al., 2016). It is necessary to seek alternative methods in the following years, such as using entomopathogenic fungi or antagonists of their mutual symbiotic fungus, to reduce the number of synthetic pesticides used to an acceptable minimum. With the purpose of microbial control of leafcutter ants, several fungi have been tested, both entomopathogenic and antagonistic to the fungus garden of the leafcutters (Folgarait et al., 2011). Among the fungi with potential for antagonistic effects, the ones belonging to the genus Trichoderma have been investigated for their effects on the development of leafcutter colonies (Menezes et al., 2010). These fungi produce compounds with broad antimicrobial activity that prevent the colonization of the substrate by other microorganisms. Once in contact, Trichoderma attacks other fungi, curling around its hyphae due to appressoria formation (Mukherjee et al., 2012). Through antibiotics and the production of different cell wall degradation enzymes, the fungus penetrates the hyphae and consequently dissolves and absorbs its walls and cellular contents (Mukherjee et al., 2013).

A strategy to better preserve the fungi used in biological control is to incorporate the fungi into baits, subsequently encapsulating them. In this preparation, the antagonistic microorganism is protected within the capsule where a nutritional source for its maintenance is provided. In the antagonistic Trichoderma spp., its proliferation is abundant, mainly when used as young mycelium with wheat bran as a food source (Cumagun, 2014).

Some chemical elements, such as cadmium, mercury, lead, and zinc, may negatively affect leafcutter ants' immune system. Besides that, zinc compounds can inhibit fungal growth and their ability to produce mycotoxins (Savi et al., 2013). Depending on the concentration, this metal can limit growth of filamentous fungi and be toxic to some microorganisms, such as bacteria and microalgae (He et al., 2011)

The objective of this work was to evaluate the effect of various concentrations of zinc sulfate on the radial growth of T. harzianum and L. gongylophorus in vitro. Subsequently, the degree of bait acceptance with the live propagule of the encapsulated fungus $T$. harzianum and zinc sulfate baits by the foraging worker ants and the effects of zinc sulfate on the development of colonies and worker mortality of $A$. sexdens were evaluated.

\section{Materials and Methods}

\subsection{Leafcutter Ant Colonies Maintenance}

The Atta sexdens colonies were started from fertilized females collected during their flight, which occurred on November 7 of 2013 at the Gurupi Campus, (Geographical coordinates: $-11.743576,-49.048799)$. They were kept in an air-conditioned room at $25{ }^{\circ} \mathrm{C}$ and $80 \% \mathrm{RH}$, with a photoperiod of $12 \mathrm{~h}$ of light in the Laboratory of Applied Functional Ecology of the Federal University of Tocantins. Experiments were conducted between July and December, 2015.

\subsection{Fungi Isolation and Culture Conditions}

The fungus T. harzianum strain ESALQ - 1306 was obtained from the commercial product Trichodermil, liquid formulation, containing at least $2.0 \times 10^{9}$ viable conidia/L of the biocontrol agent. The fungus was inoculated in Petri dishes containing PDA culture medium (Potato, Dextrose, Agar, $\mathrm{pH}=6.2$ ), which were incubated at $25 \pm 1{ }^{\circ} \mathrm{C}$, relative humidity $70 \pm 10 \%$, and with a photoperiod of $12 \mathrm{~h}$. Successive streaking were performed until the pure isolate was obtained. The symbiotic fungus L. gongylophorus was isolated from 
one of the laboratory colonies of A. sexdens. Parts of the top of the fungus garden, which had whitish hyphae, were inoculated on PDA medium $(\mathrm{pH}=5.4)$ containing chloramphenicol antibiotic $(250 \mathrm{mg} / \mathrm{mL})$. After $24 \mathrm{~h}$, the hyphae were streaked under a stereomicroscope. Petri dishes were kept in an air-conditioned room with a temperature of $25 \pm 1{ }^{\circ} \mathrm{C}$, relative humidity $70 \pm 10 \%$, and with a photoperiod of $12 \mathrm{~h}$.

For the production of T. harzianum mycelium used in the baits with encapsulated granules as a source of live fungus propagule, discs of the agar culture with the fungus were streaked in Erlenmeyer flasks of $1.000 \mathrm{~mL}$ capacity containing $400 \mathrm{~mL}$ of the Potato Dextrose (PD) liquid medium $(\mathrm{pH}=6.2$ ). The fungus remained in the container for ten days under rotary shaking at $120 \mathrm{rpm}$, incubated in the dark at $28{ }^{\circ} \mathrm{C}$. The mass of mycelium was collected and washed three times in sterile distilled water, with the excess of water removed by pressing on filter paper. Subsequently, the mass of mycelium was crushed in an electric blender.

\subsection{Effects of zinc sulfate on $T$. harzianum and Leucoagaricus gongylophorus}

In order to evaluate the effects of the zinc sulfate on the in vitro radial growth of the antagonistic fungus and the symbiotic fungus, a completely randomized experimental design was used, with ten replications, in a factorial scheme with two species of fungi (T. harzianum and $L$. gongylophorus $) \times 7$ concentrations of zinc sulfate $(0 ; 0.15 ; 0.25 ; 0.5 ; 1.5 ; 2.5$ and $5.0 \mathrm{~g} / \mathrm{L})$, considering each dish as an experimental unit. The soils of Cerrado usually have a deficiency of zinc for the cultivation of Eucalyptus. Thus, if these baits were used to control leafcutter ants in Cerrado soils, the zinc values would be diluted in the soil volume and would probably be well below the critical values, with minimal risks of toxicity to the plants. Initially, discs $(0.5 \mathrm{~cm})$ containing mycelium of the fungus were cut with a nozzle and then transferred to Petri dishes with the PDA culture medium $(\mathrm{pH}=6.2)$ of $1.5 \mathrm{~cm}$ from the edge of the dish. The dishes were previously treated with $200 \mu \mathrm{L}$ of one of the concentrations of zinc sulfate and spread with a Drigalski handle. All dishes were maintained in an incubation chamber at $25 \pm 1{ }^{\circ} \mathrm{C}$, relative humidity $70 \pm 10 \%$, and with a photoperiod of $12 \mathrm{~h}$. Diameter of the colonies of the mutualistic fungus was daily measured until the eighteenth day, whereas that of the antagonist fungus until the tenth day.

In order to evaluate the inhibition of the fungi $T$. harzianum and L. gongylophorus, diameter (in $\mathrm{mm}$ ) measurements were performed of the fungi cultures with the Petri dishes upside down. The diameters of the cultures of the antagonistic fungus were measured from the first to the tenth day, using a caliper (Insize Series 1205). As for the symbiotic fungus, the diameter was measured from the first to the eighteenth day using a binocular loupe with a millimeter ruler, since the symbiotic fungus had slow growth (Leica S8AP0).

From these measurements, the mean initial diameter (ID) and the mean final diameter (FD) of the fungus were calculated to measure the effect of each of the zinc sulfate concentrations on the fungus. Based on these values, the mean growth efficiency of the antagonistic and symbiotic fungus (E) was estimated according to the formula: $\mathrm{E}=$ FD/ID. The relative efficiency (RE) of the growth of $L$. gongylophorus and T. harzianum cultures in the presence of various concentrations of zinc sulfate was expressed about the mean of the control by the formula: $\mathrm{RE}=\mathrm{E} / \mathrm{GE}$; where GE is the growth efficiency of the antagonistic fungus and the symbiotic fungus in the absence of zinc (Nascimento et al., 2017). The growth and inhibition of fungi were estimated based on relative efficiency.

\subsection{Encapsulation of $\boldsymbol{T}$. harzianum}

The adapted methodology was used to produce the capsulated granules (Lewis and Papavizas, 1985). For the encapsulation, $5.6 \mathrm{~g}$ of sodium alginate and $5.6 \mathrm{~g}$ of orange-flavored concentrated juice powder, to increase the attractiveness of the baits, were dissolved in $190 \mathrm{~mL}$ of sterile distilled water using a magnetic stirrer. Following this, a suspension containing $10 \mathrm{~g}$ of wheat bran and $3.1 \mathrm{~g}$ of the antagonistic mycelium in $182 \mathrm{~mL}$ of sterile distilled water was prepared; $190 \mathrm{~mL}$ of the sodium alginate solution and orange concentrate was added to this suspension. This mixture was dripped with a Pasteur pipette into a $0.25 \mathrm{M} \mathrm{CaCl}_{2}$ solution under rotary shaking. The granules formed were held for 10 minutes in this solution, were washed in distilled water to remove the excess of $\mathrm{CaCl}_{2}$, and were oven-dried for two days at $26^{\circ} \mathrm{C}$. Simultaneously, the same process was carried out with the zinc sulfate baits with the minimum concentration necessary to suppress the $L$. gongylophorus fungus and not significantly inhibit the mycelial growth of the fungus T. harzianum, since one of the treatments consisted of applying the baits together. The concentration of zinc sulfate in pellets was $0.25 \mathrm{~g} / \mathrm{L}$ since this concentration obtained the best result. Thereby, a suspension containing $10 \mathrm{~g}$ of wheat bran was prepared with $182 \mathrm{~mL}$ of sterile distilled water; $190 \mathrm{~mL}$ of the solution of sodium alginate, orange juice, and zinc sulfate were added to this suspension.

\subsection{Encapsulated Bait Acceptance Tests}

Eight colonies of approximately $500 \mathrm{~mL}$ of fungal sponge were used, with two colonies for each treatment. The treatments consisted of encapsulated baits without the mycelium and zinc sulfate (T1, control); encapsulated baits with $T$. harzianum mycelium (T2); encapsulated baits with zinc sulfate (T3); and encapsulated baits containing zinc sulfate and T. harzianum (T4). 
The baits were offered in Petri dishes $(90 \mathrm{~mm}$ diameter) daily for 15 days. During the first 14 days, amount of bait offered daily was 2 grams for all the treatment groups except for T4: one gram containing zinc sulfate in one dish and one gram of bait based on $T$. harzianum in the other. On the last day of treatment (day 15), the baits were offered ad libitum (saturation). On this day, there was no weighing of the non-transported baits and no measurement of the first bait pellet's transport time. The non-transported and unincorporated baits were weighed in an analytical balance, and the symbiotic fungus volume was measured at the end of the treatment (15 days). All colonies had the same volume of fungus at the start of experiments, considering that the colonies' containers were full. The observation of the acceptance of the baits (collection and transport to the colony) lasted 30 minutes. At the end of this time, the remaining baits were collected and weighed to verify the value of the mass transported.

The granules were packed in plastic containers in an incubated chamber at a temperature of $26{ }^{\circ} \mathrm{C}$ and in complete darkness to evaluate $T$. harzianum bait viability. Four granules were removed each month and placed in sterile Petri dishes in PDA medium. For the analysis of variation in volume of the symbiotic fungus, the colony's plastic container (height $9 \mathrm{~cm}, 500 \mathrm{~mL}$ of volume) was graduated in three intervals of three centimeters each. The variation of the fungal volume was subsequently estimated by visual analysis. During the process of transport and incorporation of the baits, the final destination of the baits taken by the workers was observed to verify their time inside the nest if these encapsulates were carried subsequently to different places in the garbage, or the fungal garden. The residues produced by the colonies were dried for approximately 4 hours at $40^{\circ} \mathrm{C}$ and weighed. The dead workers were also counted at the end of the 15 days of the experiment.

\subsection{Statistical Analysis}

Statistical differences between the growth of the antagonistic fungus and the symbiotic fungus against zinc sulfate concentrations were evaluated using the Kruskal Wallis non-parametric ANOVA ( $\alpha=5 \%)$, followed by the Bonferroni test for multiple comparisons using the Action Stat software (www.portalaction.com.br).

Statistical analysis of the average time of acceptance, number of baits carried during the time that they were offered to the workers (30 $\mathrm{min}$ ), volume variation in the colonies, volume of waste produced, and the number of dead workers were descriptive because only a limited number of colonies were tested for each treatment.

\section{Results and Discussion}

There was a significant difference in the relative efficiency of the growth of L. gongylophorus (KruskalWallis test: $\mathrm{H}(6, \mathrm{~N}=70)=44.35, \mathrm{p}<0.001)$ (Figure 1) and that of $T$. harzianum (Kruskal-Wallis test: $\mathrm{H}(6, \mathrm{~N}=70)=$ 23.03, p < 0.001) (Figure 2) in varying concentrations of zinc sulfate. A lower concentration of zinc sulfate $(0.15$ $\mathrm{g} / \mathrm{L})$ did not interfere in the radial growth of $L$. gongylophorus. However, other concentrations of zinc sulfate $(0.25 ; 0.5 ; 1.5 ; 2.5$ and $5.0 \mathrm{~g} / \mathrm{L})$ suppressed the symbiotic fungus' growth.

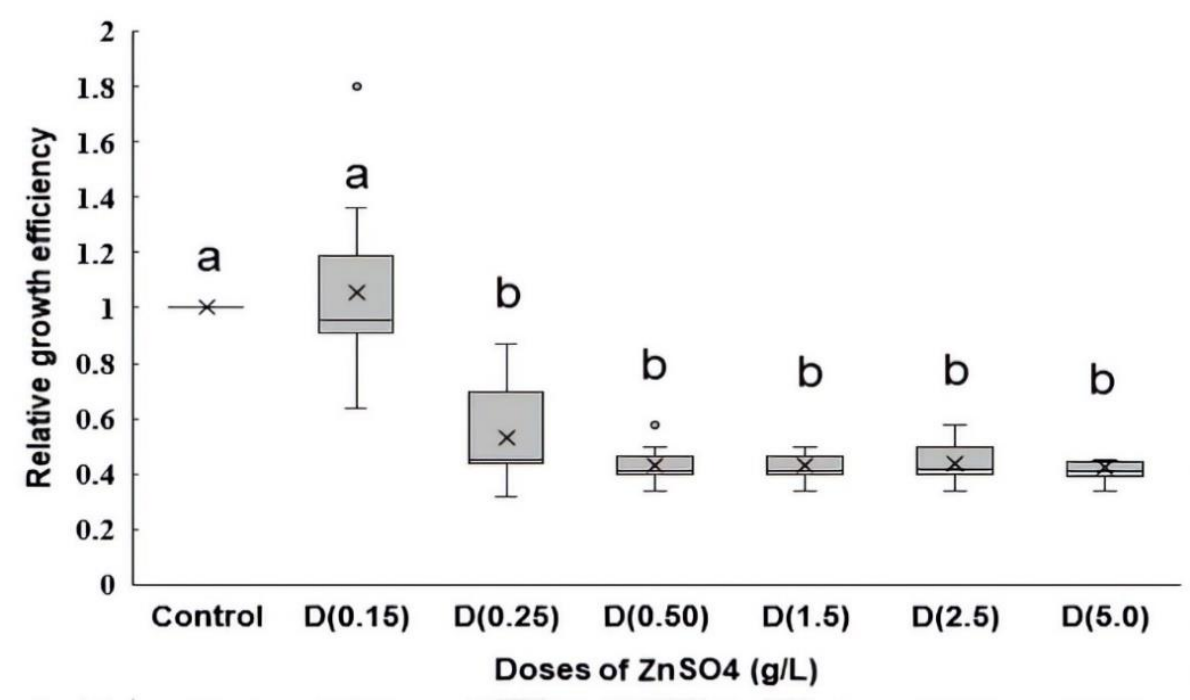

Figure 1. Relative growth efficiency of Leucoagaricus gongylophorus in varying concentrations of zinc sulfate $\left(\mathrm{ZnSO}_{4}\right) \mathrm{g} / \mathrm{L}$ compared to control group. Same letter indicates no significant difference based on the Bonferroni test $(\alpha=0.05)$. The symbol $\times$ represents the means, boxes represent the upper and lower quartiles, bars represent the maximum and minimum values, and the point represents the outlier value. 


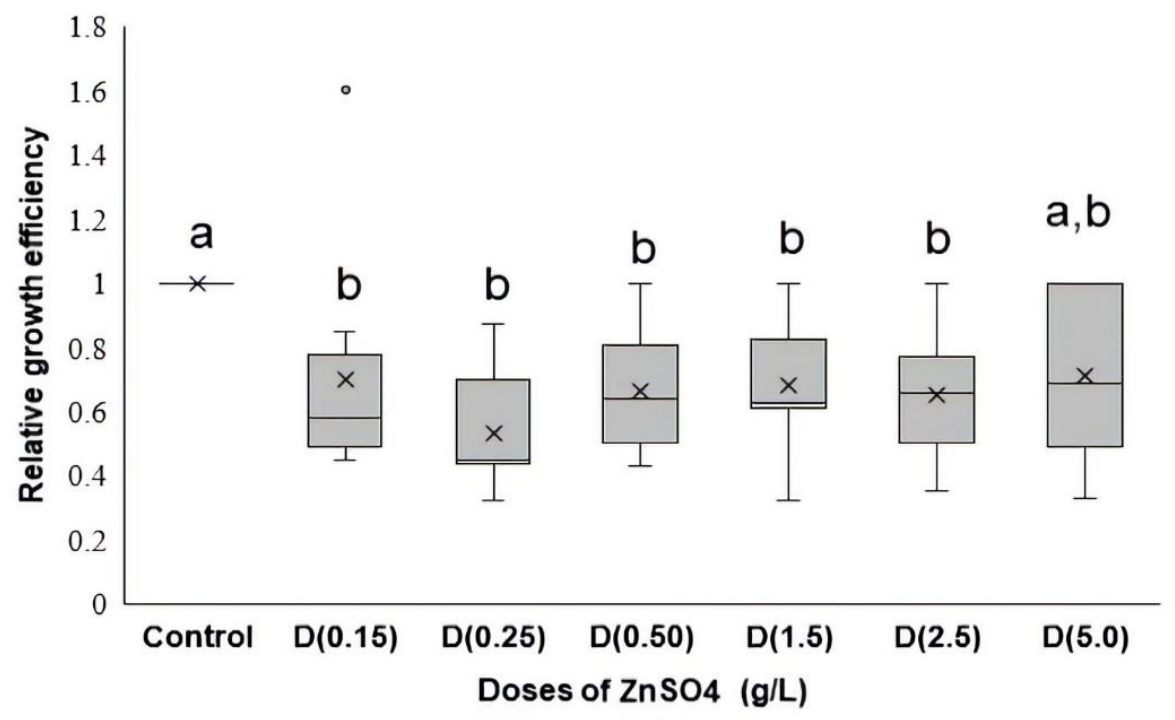

Figure 2. Relative growth efficiency of Trichoderma harzianum in varying concentrations of zinc sulfate $\left(\mathrm{ZnSO}_{4}\right) \mathrm{g} / \mathrm{L}$ compared to control group. Same letter indicates no significant difference based on the Bonferroni test $(\alpha=0.05)$. The symbol $\times$ represents the means, boxes represent the upper and lower quartiles, bars represent the maximum and minimum values, and the point represents the outlier value.

In the bait acceptance test, the average time for the first pellet's acceptance was $4.2 \pm 2.73 \mathrm{~min}$, with the workers transporting approximately $40 \%$ of the total amount of the granules available for consumption throughout the experiment (Table 1). The colonies treated with zinc sulfate $+T$. harzianum (T4) were those that carried the most substantial amount of baits; however, the first pellet's transport time was higher than that of the control baits. The baits containing the encapsulated $T$. harzianum fungus were very attractive (T2) because they were initially most quickly transported to the colonies' interior. This was observed when the two treatments were applied together (T4). These granules had an average diameter of 2 millimeters and a mass of \pm 0.02 grams.
At the end of 15 days, the colonies that received the baits containing the antagonistic T. harzianum continued with the same coloration, unlike the colonies that received baits containing zinc sulfate in their formulation (T3), in which fungal sponges presented firmer and "rubbery" consistency and yellowish color. These same characteristics were observed when the zinc sulfate was applied in combination with $T$. harzianum (T4).

Control colonies (T1) showed no change in fungus volume, hence their containers retained $100 \%$ of the volume. However, all other treatments caused a reduction in fungal sponge volume, with greater reductions in the colonies that received both $\mathrm{ZnSO}_{4}$ and $T$. harzianum (T4), 35\% (Table 2).

Table 1. Average number \pm standard deviation (SD) and percentage of baits transported in each treatment $(n=2$ colonies $)$ and mean time (MT) in minutes for the transport of the first bait pellet. The duration of the test for each colony was 15 days: (T1, control): encapsulated baits without the mycelium and zinc sulfate; (T2) encapsulated baits with T. harzianum mycelium; (T3) encapsulated baits with zinc sulfate and (T4) encapsulated baits containing zinc sulfate and T. harzianum.

\begin{tabular}{cccc}
\hline Treatment & Total $(\mathrm{g}) \pm$ SD & Total $(\%)$ & MT (min) \\
\hline T1 & $15.3 \pm 1.14$ & 27.3 & $3.3 \pm 3.07$ \\
T2 & $25.0 \pm 0.91$ & 44.6 & $2.3 \pm 1.98$ \\
T3 & $20.1 \pm 1.38$ & 35.9 & $5.9 \pm 5.83$ \\
T4 & $32.1 \pm 1.02$ & 57.3 & $5.4 \pm 3.66$ \\
\hline
\end{tabular}

Table 2. Average \pm standard deviation (SD) of the number of dead workers, dry weight of the colonies' waste, and variation of the fungus garden volume in each treatment, with two colonies per treatment at the end of 15 days of evaluation. (T1, control): encapsulated baits without the mycelium and zinc sulfate; (T2) encapsulated baits with T. harzianum mycelium; (T3) encapsulated baits with zinc sulfate and (T4) encapsulated baits containing zinc sulfate and T. harzianum.

\begin{tabular}{cccc}
\hline Treatment & Dead Workers & Waste $(\mathrm{g})$ & \% Variation of the Fungus Garden Volume \\
\hline T1 & $35.00 \pm 5.91$ & $5.88 \pm 2.42$ & 0 \\
T2 & $85.00 \pm 9.21$ & $10.05 \pm 3.17$ & $-30.50 \pm 3.50$ \\
T3 & $92.00 \pm 9.60$ & $11.67 \pm 3.41$ & $-19.50 \pm 3.50$ \\
T4 & $120.00 \pm 10.95$ & $15.00 \pm 3.87$ & $-35.00 \pm 5.70$ \\
\hline
\end{tabular}


Combined treatment with baits containing $\mathrm{ZnSO}_{4}$ and T. harzianum also resulted in higher mortality of workers and higher production of waste from the colony, which indicates the death of the symbiotic fungus $L$. gongylophorus (Table 2).

The symbiotic fungus L. gongylophorus cultivated by leafcutter ants grew slowly in the laboratory, interrupted in its radial growth, not reaching the edges of the dishes even after weeks of incubation (Souza et al., 2011). When maintained in an environment with different conditions, such as exposure to heavy metals, this fungus can, similar to other species, reduce its metabolism and cell growth, because the cells reduce the energy spent for growth (Gadd and Raven, 2010). Such modifications may be related to alterations in the structure of the cytoplasmic membrane; this produces progressive alterations of form and loss of metabolic activity, resulting in the reduction and inhibition of growth (Anahid et al., 2011). Therefore, considering the different effects of zinc sulfate on the two species of fungi studied, our study indicates that these baits are promising; however, field testing is required where conditions are very different from the laboratory. The size of the colonies needs to be taken into account to determine the efficiency of the baits.

Zinc is a fundamental element for fungus metabolism, helping and maintaining the integrity of ribosomes and biological membranes, and is also required for their growth. Nevertheless, high concentrations of this metal may be inhibitory or toxic to the cell and its growth, besides reducing respiration and spore germination (Savi et al., 2013). In our study, lower doses of $\mathrm{Zn}$ had no inhibitory effect on T. harzianum. Conversely, another study has observed decrease in the radial growth of different fungal species of Trichoderma, Rhizopus, and Fusarium genera in the presence of zinc and other metals (Datta, 2015). Zinc compounds, particularly $\mathrm{ZnSO}_{4}$ and $\mathrm{Zn}\left(\mathrm{ClO}_{4}\right)_{2}$, showed antifungal effects, exhibiting antimycotoxin activity and causing changes in the cellular structure of fungi such as Gibberella zeae (Schwein.) Petch (1936), Penicillium citrinum Thom. (1910), and Aspergillus flavus Link. 1809) (Savi et al., 2013).

Mass and time are factors directly related to the granules' acceptance because in addition to attracting the ants, the baits must possess physical characteristics that make them easy to be picked up and carried. The abundant offer of baits on the last day of application (saturation) allowed us to verify that there was abandonment or rejection of the baits carried into the colony. This leads us to believe that attractiveness is higher when these baits are offered in smaller quantities. Therefore, a dosage acceptable by the ants and at the same time which affects the colony must be verified.

The genus Trichoderma is extensively studied worldwide as a biological control; however, there are limitations to using it for leafcutter ant control, including the absence of appropriate formulations for these social insects. Encapsulation baits could ensure the microbial agent's viability and efficiency to their application in the field. The formulations of encapsulated granules containing live propagules of the fungus T. harzianum and zinc sulfate were accepted by ants, carried to the colonies' interior, and incorporated into the fungus garden of the leafcutter ant A. sexdens. Baits containing wheat bran as a food source were attractive and viable at a controlled temperature of $26^{\circ} \mathrm{C}$ for at least four months.

\section{Conclusions}

The baits did not promote the death of ant colonies; however, they reduce the volume of the symbiotic fungus L. gongylophorus of laboratory colonies.

\section{Acknowledgements}

This work was supported by the National Council for Scientific and Technological Development (CNPq), Brazil (403708-2013-3).

\section{Bibliographic References}

Anahid, S., Yaghmaei, S., Ghobadinejad, Z., 2011. Heavy metal tolerance of fungi. Scientia Iranica, 18(3), 502-508.

Aylward, F.O., Burnum-Johnson, K.E., Scott, J.J., Suen, G., Tringe, S.G., Adams, S.M., Barry, K.W., Nicora, C.D., Piehowski, P.D., Purvine, S.O., Starrett, G.J., Goodwin, L.A., Smith, R.D., Lipton, M.S., Currie, C.R., 2012. Metagenomic and metaproteomic insights into bacterial communities in leafcutter ant fungus gardens. Multidisciplinary Journal of Microbial Ecology, 6(9), 1688-1701.

Cumagun, C.J.R., 2014. Advances in Formulation of Trichoderma for Biocontrol, in: Gupta, V., Schmoll, M., Herrera-Estrella, A., Upadhyay, R.S., Druzhinina I., Tuohy, M., (Eds.). Biotechnology and Biology of Trichoderma. Elsevier, Amsterdam, 527-531.

Datta, B., 2015. Heavy metal tolerance of filamentous fungi isolated from metal- contaminated soil. Asian Journal of Microbiology, Biotechnology and Environmental Sciences, 17(4), 965-968.

Della Lucia, T.M.C., 2011. Formigas-Cortadeiras: da Bioecologia ao Manejo, primeira ed. UFV, Viçosa.

Della Lucia, T.M.C., Gandra, L., Guedes, R., 2014. Managing leaf-cutting ants: peculiarities, trends and challenges. Pest Management Science, 70(1), 14-23.

Fine Licht, H.H., Boomsma, J.J., Tunlid, A., 2014. Symbiotic adaptations in the fungal cultivar of leaf-cutting ants. Nature Communications, 5, 5675.

Folgarait, P., Gorosito, N., Poulsen, M., Currie, C.R., 2011. Preliminary in vitro insights into the use of natural fungal pathogens of leaf-cutting ants as biocontrol agents. Current Microbiology, 63(3), 250-258. 
FSC, 2017. FSC® List of 'highly hazardous' pesticides. https://ic.fsc.org/file-download.fsc-list-of-highly-hazardouspesticides.a-2951.pdf (Accessed July 12, 2020).

Gadd, G.M., Raven, J.A., 2010. Geomicrobiology of Eukaryotic Microorganisms. Geomicrobiology Journal, 27(67), 491-519.

He, L., Liu, Y., Mustapha, A., Lin, M., 2011. Antifungal activity of zinc oxide nanoparticles against Botrytis cinerea and Penicillium expansum. Microbiological Research, 166(3), 207215.

Lange, L., Grell, M.N., 2014. The prominent role of fungi and fungal enzymes in the ant-fungus biomass conversion symbiosis. Applied Microbiology and Biotechnology, 98(11), 4839-4851.

Lewis, J.A., Papavizas, G.C., 1985. Characteristics of alginate pellets formulated with Trichoderma and Gliocladium and their effect on the proliferation of the fungi in soil. Plant Pathology, 34(4), 571-577.

Menezes, J.P., Junges, E., Blume, E., Pereira, M.E., 2010. Toxicologia do biopreparado à base de Trichoderma sp. (Isolado UFSM T17) administrado em mamífero. Revista da Faculdade de Zootecnia, Veterinária e Agronomia (FZVA), 17(1), 28-40.

Montoya-Lerma, J., Giraldo-Echeverri, C., Armbrecht, I., FarjiBrener, A., Calle, Z., 2012. Leaf-cutting ants revisited: Towards rational management and control. International Journal of Pest Management, 58(3), 225-247.

Mukherjee, M., Mukherjee, P.K., Horwitz, B.A., Zachow, C., Berg, G., Zeilinger, S., 2012. Trichoderma-plant-pathogen interactions: advances in genetics of biological control. Indian Journal of Microbiology, 52(4), 522-529.
Mukherjee, P.K., Horwitz, B.A., Herrera-Estrella, A., Schmoll, M., Kenerley, C.M., 2013. Trichoderma research in the Genome Era. Annual Review of Phytopathology, 51(1), 105129.

Nascimento, M.O., Almeida Sarmento, R., Santos, G.R., Oliveira, C.A., Souza, D.J., 2017. Antagonism of Trichoderma isolates against Leucoagaricus gongylophorus (Singer) Möller. Journal of Basic Microbiology, 57(8), 699-704.

Savi, G.D., Bortoluzzi, A.J., Scussel, V.M., 2013. Antifungal properties of Zinc-compounds against toxigenic fungi and mycotoxin. International Journal of Food Science and Technology, 48(9), 1834-1840.

Souza, M.D., Peres Filho, O., Caldeira, S.F., Pelissari, A.L., Dorval, A., 2011. Análise de agrupamento e regressão nãolinear aplicados ao crescimento in vitro de Leucoagaricus gongylophorus (Singer) Möller em meios de cultura acrescido com diferentes extratos vegetais. Biotemas, 24(4), 85-93.

Ward, P.S., Brady, S.G., Fisher, B.L., Schultz, T.R., 2015. The evolution of myrmicine ants: phylogeny and biogeography of a hyperdiverse ant clade (Hymenoptera: Formicidae). Systematic Entomology, 40(1), 61-81.

Zanuncio, J.C., Lemes, P.G., Antunes, L.R., Maia, J.L.S., Mendes, J.E.P., Tanganelli, K.M., Salvador, J.F., Serrão, J.E., 2016. The impact of the Forest Stewardship Council (FSC) pesticide policy on the management of leaf-cutting ants and termites in certified forests in Brazil. Annals of Forest Science, 73(2), 205-214. 